\title{
Controlled Creating of Cracks in Concrete for Non-destructive Testing
}

\author{
Herbert Wiggenhauser $^{1} \mathbb{D} \cdot$ Christian Köpp $^{1} \cdot$ Juri Timofeev $^{1} \cdot$ Hoda Azari $^{2}$
}

Received: 12 October 2017 / Accepted: 26 July 2018 / Published online: 17 August 2018

(c) The Author(s) 2018

\begin{abstract}
The non-destructive assessment of cracks in concrete is a common task for which non-destructive evaluation solutions have been published. Primarily, these tests have been carried out on artificial cracks that have been created by using notches instead of natural cracks. This study evaluates a procedure designed to create reproducible and controlled cracks in concrete. The procedure is based on using expanding mortar in a series of blind holes. This is done in combination with carefully aligned reinforcement to guide the direction of the crack development. The depth of the crack is also controlled by reinforcement. Crack depth varies statistically in the range of the maximum aggregate size $(16 \mathrm{~mm})$ used for concrete.
\end{abstract}

Keywords Non-destructive testing of concrete $\cdot$ Cracks $\cdot$ Reference specimen

\section{Introduction}

Concrete is used all over the world to build a large variety of structures like houses, bridges, roads, dams and foundations. It is the most widely used material in the world [1] and can be produced from local materials that are available everywhere. The positive performance of concrete has led to the design and construction of worldwide recognized landmark structures. The combination of concrete with steel and post-tensioning (PT) enables architects and engineers to design and construct very tall concrete structures or long span bridges.

Concrete is a very durable material and can withstand large loads over a time period of many decades. Deterioration processes, which affect the durability initiate with depassivation of reinforcement by carbonation or chloride diffusion, can lead to corrosion of the rebars. Such processes depend on the resistance of the concrete material to the transport of ions, moisture, and gases such as carbon dioxide. The density of concrete against permeation of gases and liquids and

$凶$ Herbert Wiggenhauser

hwiggenh@gmail.com

Hoda Azari

Hoda.Azari@dot.gov

1 Bundesanstalt für Materialforschung und -prüfung (BAM), Unter den Eichen 87, 12205 Berlin, Germany

2 Federal Highway Administration, Turner-Fairbank Highway Research Center, 6300 Georgetown Pike, McLean, VA 22101, USA the required $\mathrm{pH}$ value represent an effective shield against these attacks [2]. However, the presence of cracks can destroy this protection because the transport along the cracks is very effective and fast. Design specifications ensure that the concrete quality and the tolerated crack opening width meet the requirements. For the inspection of concrete structures, among a variety of test tasks [3], crack measurement is one of the most important ones.

Cracks are natural features in concrete that can vary over a large range of sizes and be formed in different shapes [4]. On a small scale, microcracks may be invisible to the human eye; they may form between cement matrix and aggregates or within the cementitious material. They are mainly caused by mechanical stresses or due to chemical reactions, vibrations, freeze-thaw, or temperature effects. While affecting the mechanical material properties of concrete, these microcracks will also lower the resistance against the transport processes described above, especially when they connect and form larger cracks.

Per definition, a crack is a break without a complete separation of parts. Crack direction, depth, shape, and surface opening are parameters that characterize a crack and have to be controlled in the process of initiating a crack of predefined properties. The crack depth is the main property which determines the durability of a reinforced concrete (RC) structure because it reduces the carbonation protection of the reinforcing steel. The definition of a crack's depth in concrete is particularly difficult because of its transition into the pore structure and interfaces between aggregates and cementitious 
matrix. There can also be contacts between the crack flanks, while further down the crack opens again. The deep part of the crack, which allows the diffusion of moisture, carbon dioxide, and chlorides is the determining factor for the durability.

According to standards, cracks which have an opening width of less than $0.2 \mathrm{~mm}$ [5] are tolerated, e.g. for bridges in Germany. Larger cracks may reduce the corrosion protection for reinforcement dramatically when their extension reaches these steel elements. Engineers evaluate the crack pattern and decide if actions have to be taken. Dye injection into existing cracks and coring are both common practice used to establish the ground truth [6]. A more complete penetration is achieved by vacuum intrusion [2], especially when using fluorescence dye under ultraviolet excitation. In either situation, the crack depth is determined visually. An experienced person can follow the crack and define the crack depth. Petrographic Methods [7] for crack evaluation in concrete are highly developed and used regularly on samples in laboratories.

Alternatively, non-destructive test methods can be used to evaluate the crack instead of destructive methods. Typically, non-destructive research is conducted on notches as representatives of cracks. While these studies are of high importance for development of reliable nondestructive Evaluation (NDE) solutions, the comparability of NDE results from obtained from a notch as opposed to NDE results obtained from a naturally-occurring crack is difficult.

Non-destructive test methods for crack assessment focus on crack depth measurements, a property which is not very well defined. Typically, a natural crack in concrete is of a three-dimensional irregular shape that can change directions and orientation. In addition, cracks can be bridged by aggregates or closed without bonding. There is no reference crack available which could be created and utilized in any laboratory.

This study describes the procedure for creating a specific type of crack in a concrete specimen with predefined properties. The crack should be visible at the surface with an opening of $0.2 \mathrm{~mm}$ and its orientation has to be perpendicular into the body of the specimen. The shape of the crack should be as planar as possible and the crack depth should have little variation along its length.

\section{Non-destructive Testing (NDT) of Cracks in Concrete}

Crack detection in reinforced concrete has been a consistent subject of research and various methods have been investigated for crack detection. Particularly promising are methods for crack detection using acoustic methods, which can be classified as follows: resonance methods, ultrasound-pulse methods, the surface wave method and the acoustic emission method [8]. Especially promising are impact echo and ultrasonic pulse (echo or transmission) methods which seem to have the potential of crack depth determination.

In general, different wave types and different methods are used for determining the crack depth. The following methods are widely used: Time of Flight Diffraction (TOFD), nonlinear mixing of ultrasound coda waves, and Total Focusing Method (TFM) [9]. The transient elastic waves method allows for the creation of a three-dimensional image of the crack [10].

TOFD is based on a simple geometrical model and its application is relatively uncomplicated. TOFD or diffraction time measurement is based on the elapsed time of the diffracted sound wave around the crack tip. The depth of the crack is determined through the propagation time of the diffracted signals. TOFD was primarily used in steel, especially for the inspection of welded beams, but can also be used in other materials according to DIN EN 583-6 [11]. The advantages of the method are: only one-sided access necessary, the possibility of variable arrangements (transducer, angle of impacting) and the time required for the measurement as well as the ability of calculation of the crack depth. Some disadvantages of the method are: the presence of "dead zones" (surface, back wall) in accordance with DIN EN 5836 [11], which can conceal the signals associated with the respective crack, and the difficult distinction between material inhomogeneity and a crack.

The impact echo method is usually applied for the detection of cracks oriented parallel to the surface (such as delaminations) and also for surface-opening cracks in reinforced concrete, which run mostly vertical to the surface [12].

Cracks can also be detected by observing changes in the signal amplitude or energy, while the depth of the crack remains unknown [13, 14]. In the experiment reported in [13], real cracks were generated by applying mechanical force with a hammer.

Another study has shown that the depth of crack can be approximated using ultrasound pulses. In this study, a depth of approximately $20 \%$ higher than the actual depth has been measured for cracks with a crack width of $0.2-10 \mathrm{~mm}$ [15].

One study [16] investigated real cracks and notches, in addition sound bridges were inserted to create a more realistic test scenario. The verification of the results was carried out destructively.

The ultrasonic echo method has also been used to investigate the differences between the detection of empty and repaired cracks [17].

A computational intense data analysis method is Reverse Time Migration (RTM) which can be used to visualize cracks. Reverse Time Migration (RTM) was developed for geophysics [18] and is adapted for concrete applications. In this method, the following steps are carried out: selection 
of a speed model for the component, forward modeling of a wave field, reverse propagation of the data and superposition of the data from the first two steps by means of a cross correlation. An advantage of this method is the potential to localize boundary surfaces of arbitrary orientation, lower edges of inhomogeneities, and inclined reflectors by means of multiple reflections. A disadvantage of the method is an enormously high computing power and large memory requirement. A further disadvantage is a poor imaging of lower edges, such as the underside of a hole.

Radiography is a non-destructive test method used to determine crack properties and visualize them in 3D using Computed Tomography [2, 19]. However, for practical and technical reasons, the sample size for such experiments may be very small and this technique cannot be used for larger specimens or outside the laboratory.

\section{Principle of Crack Creation}

Cracks in concrete can be initiated in many different ways, but the challenge is to create cracks of reproducible quantities which are stable and do not change over time. The forces which cause concrete to crack must be controlled in a way that the crack opens in a predefined direction and stops at a point where the desired crack dimensions and shape have been reached. With regard to engineering rules, the whole arrangement may not completely fulfill the requirements of a RC element, but should be as close as possible to a situation generally found in practice, e.g. the reinforcements are placed to optimize the crack development and not according to standards.

Betonamit, a swelling clay material $[20,21]$, is filled into blind holes to apply the necessary force to create the crack. The reinforcement acts as a counterforce to the expanding mortar. The reinforcement at the bottom of the specimen, opposite to the surface where the blind holes are placed, ensure that the crack will not expand through the specimen. The middle reinforcement limits the crack depth depending on its vertical (Z-direction) position. The expanding mortar applies the force against the reinforcement. The amount of Betonamit injected in the blind holes ultimately determines the properties of the created crack.

Betonamit was chosen as expanding grout material to initiate the cracking because the force can be controlled by the amount of grout applied into the blind hole. Blind holes aligned in a line and of equal depth and diameter are used to guide the direction and shape of the crack. After mixing, the grout is filled into those blind holes and the pressure builds up over the next few days. Typically, after $24 \mathrm{~h}$ the crack becomes visible as a hairline and opens over the next $48 \mathrm{~h}$. Further growth of the crack is limited by reinforcement which is oriented perpendicular to the crack direction. Crack

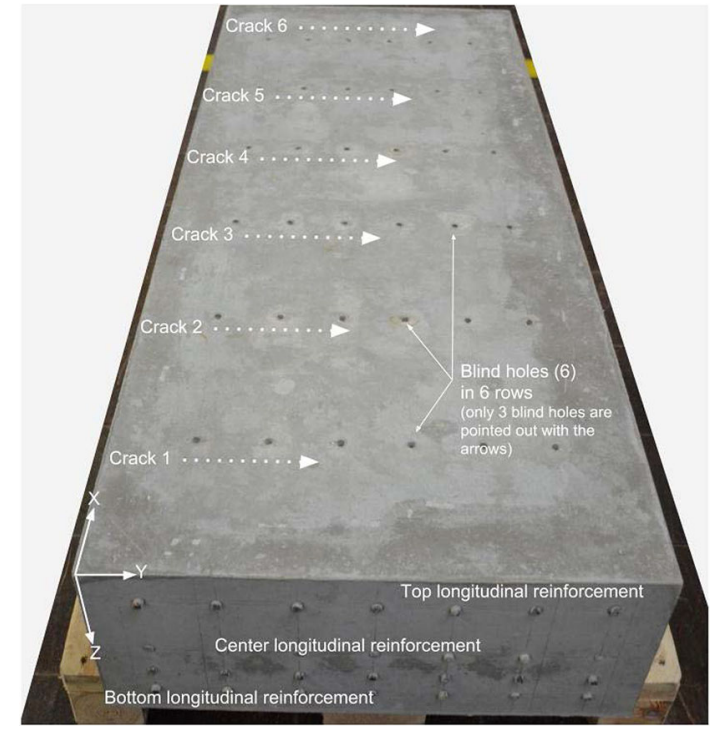

Fig. 1 Photograph of crack specimen after removal of formwork. The blind holes are filled with expansive mortar. Cracks are formed along the dotted arrow directions. The longitudinal reinforcement controls the crack width and depth. The depth of the center reinforcement can be varied by $40 \mathrm{~mm}$ up or down to control the crack depth. (The apparent second row of center reinforcement is concrete which filled the blind holes in the formwork which were prepared for the alternate position of the rebars.) (see text for details)

depth is controlled by a layer of additional reinforcement, in a given depth parallel to the surface of the specimen (see Fig. 1).

The optimal procedure was found by varying the parameters, e.g. reinforcement position, blind hole diameter, depth and distance, and fill level of expansive grout.

Four quantities of the cracks were selected to be able to characterize them and to make them comparable: "Alignment", "Depth", "Shape", and "Width." These properties are summarized and described in Table 1 and used for the analysis of the cracks.

\section{Formwork, Reinforcement and Concrete}

The formwork with reinforcements and plastic rods for creating the blind holes is prepared in the laboratory. The $\mathrm{X}$-side is the longitudinal side of the specimen, $Y$ the crosswise width and the direction of the cracks, and $\mathrm{Z}$ the depth or thickness direction ( $Z=0$ is the top side where the cracks are visible).

The enclosing wooden form is made of robust coated plywood (21 mm thick) which will not bulge under the weight of the poured concrete. The bottom (horizontal) plate has six rows of six plastic rods each ( $8 \mathrm{~mm}$ in diameter, $50 \mathrm{~mm}$ long) in the crosswise direction, which are used to create the blind holes in which the expansive mortar will be filled to create the cracks. This ensures that all blind holes have exactly the 
Table 1 Properties of surface opening cracks in concrete, their definition and quantification

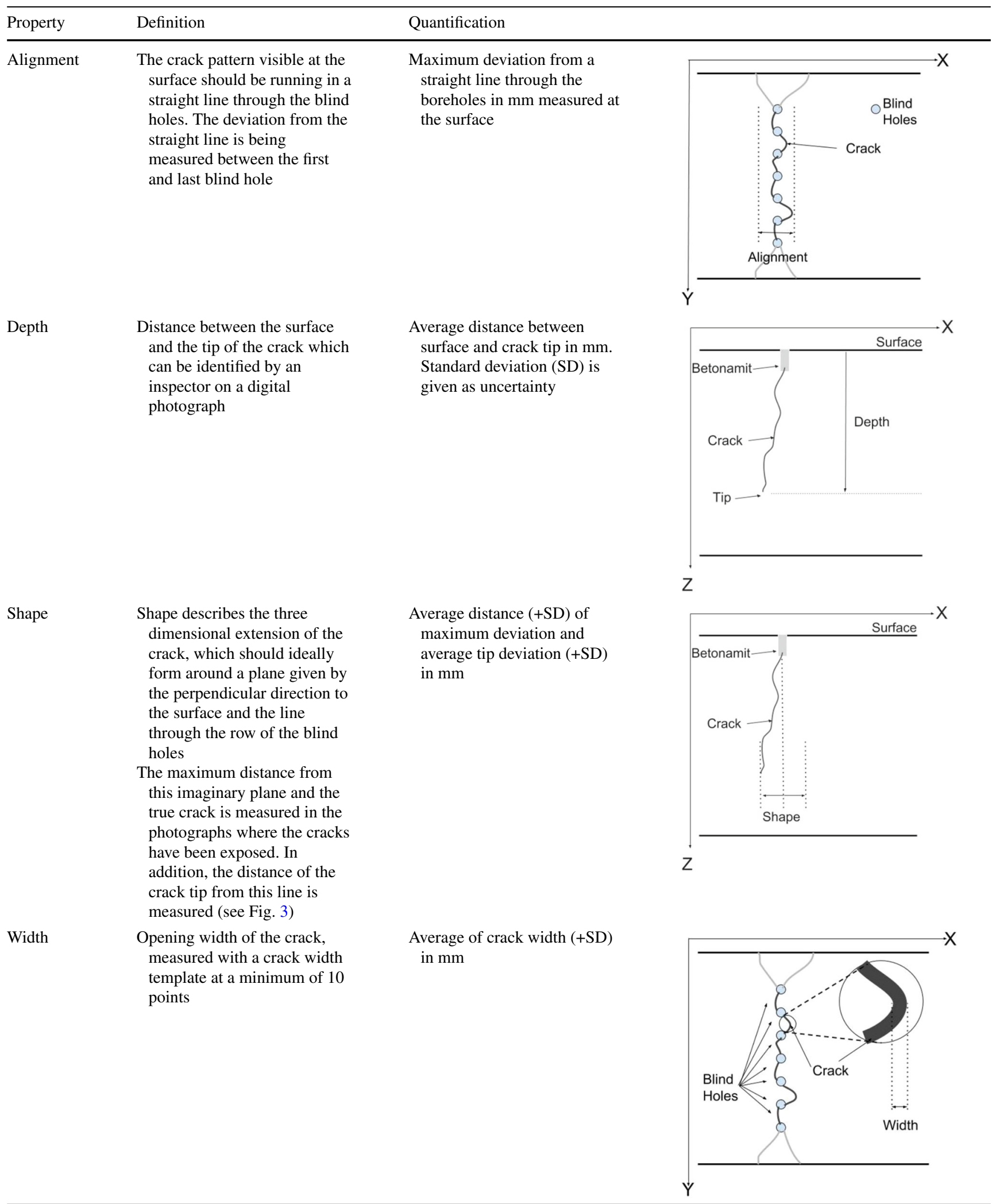


same diameter, depth and orientation. The side with the blind holes becomes the top side of the specimen when the concrete has hardened and the formwork removed.

In addition, the side panels of the formwork have blind holes to position the reinforcement rods as described below. Single reinforcement rods were used to ensure an exact positioning in the formwork.

Three horizontal layers of reinforcement are applied to control the crack dimensions:

(A) The top layer consists of longitudinal and crosswise bars. The longitudinal bars (X-direction) are aligned in the center between the rows of blind holes, perpendicular to the crack direction. The crack opening is controlled by these bars. In the crosswise direction (Y-direction), reinforcement bars (12 $\mathrm{mm} \emptyset$, all others have $8 \mathrm{~mm} \emptyset$ ) are positioned $40 \mathrm{~mm}$ left and right of line through the blind holes to control the direction of crack development. The concrete cover of this layer is $40 \mathrm{~mm}$.

(B) The center reinforcement layer is used to control the crack depth. The longitudinal rods are parallel to the rods in the top layer. The crosswise aligned rods are positioned in the center between the blind hole rows. They are used to stabilize the alignment of the longitudinal rods. The whole center reinforcement layer can be shifted $40 \mathrm{~mm}$ up or down in vertical direction to influence the crack depth.

(C) The lower layer is a copy of the center reinforcement layer (B) at the bottom of the specimen with a concrete cover (from the bottom) of $40 \mathrm{~mm}$.

The formwork can be used several times and is manufactured with high precision to reduce the variability in the crack development by exactly placed reinforcement.

After the concrete has been poured and hardened (concrete mix: C 30/37), the formwork can be removed. The plastic rods can be carefully extracted using a suitable tool, e.g. a crowbar, provided they had been treated with formwork fat or oil prior to the concrete pour.

The hardened specimen is shown in Fig. 1 after formwork removal. The size of the specimen is $1500 \times 600 \times 250 \mathrm{~mm}^{3}$. The distance between the rows of blind holes is $225 \mathrm{~mm}$, the spacing between the holes $80 \mathrm{~mm}$. Along the six rows of blind holes the cracks develop after the expansive mortar has been filled into the blind holes.

\section{Crack Creation and Depth Evaluation}

After the specimen has been cured for at least 28 days, it is prepared for crack creation. The blind holes must be widened and their depth extended if necessary. The best results were found for a blind hole diameter of $10 \mathrm{~mm}$ and a depth $60 \mathrm{~mm}$ (filling height $50 \mathrm{~mm}$, see below).

The blind holes are cleaned and the expansive mortar (Betonamit) is mixed as described in the operation manual provided by the manufacturer. This material should be stored under dry conditions and sealed from the atmosphere. It was noticed during early tests that the mortar properties change when stored under atmospheric condition and may not create the cracks as intended.

The prepared mortar is filled into the blind holes using a spatula of appropriate dimensions. The filling level should be $10-15 \mathrm{~mm}$ below the surface of the specimen to reduce the risk of breaking the concrete at the surface around the blind hole. It is not necessary to seal the exposed mortar at the top of the filling.

Typically, the crack develops within $12 \mathrm{~h}$ after the mortar has been filled in. The expansion process gradually slows and usually finishes after $72 \mathrm{~h}$. At this point the crack should be clearly visible and follow a line given by the arrangement of the blind holes. From the blind holes at the end of each row, a $\mathrm{V}$-shaped crack pattern may evolve. This does not affect the crack development in the area between the outer blind holes.

There is no standard procedure to determine the true crack depth. Experiments with colored liquid, which penetrate the crack and color the crack faces, can be used. For very fine cracks, the penetration may not reach the tip of the crack. In this study, the specimen was cut in slices to visually access the cracks at several positions. The cuts were aligned through each row of blind holes along the long axis of the specimen, perpendicular to the crack direction. The cutting procedure involves heavy equipment which introduces strong vibrations into the specimen. To prevent the cracks from further opening during this treatment and subsequent handling, the cracks were fixed with low viscosity and fluorescent resin as shown in Fig. 2.

The specimen is cut into seven slices from which only the inner five with 10 surfaces are used for the cracks analysis. The cuts are aligned directly through the rows of blind holes parallel to the longitudinal axis of the specimen and perpendicular to the cracks' direction. Each crack is then photographed with high resolution $(6000 \times 4000,4288 \times$ 3216 and $3840 \times 2160$ pixel were used) and good lighting conditions under stable position of the camera on a tripod. A template was utilized for the photographs to support the post-analysis on the computer screen (Fig. 2). From each specimen, $10 \times 6$ photographs of the cracks are made from the surfaces of the 5 inner slices.

The photographs of each crack were analyzed on screen by several people, from a variety of backgrounds, expertise, and experience.

The resin has proven to be very helpful and guides the inspector's eye to follow the crack. In some situations, the 


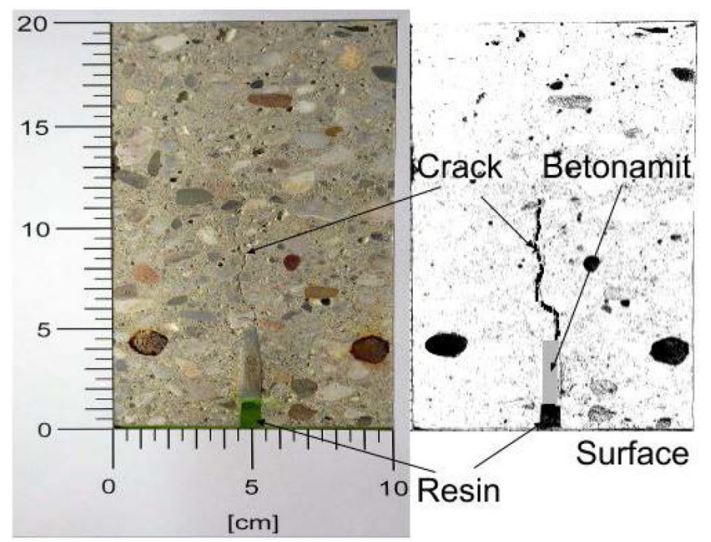

Fig. 2 Left: Photograph of crack with template to measure depth and shape of crack. Right: Processed Image with enhanced crack visibility. Betonamit is visible as grey material in the blind hole. The resign is visible as the green material at the surface and in the blind hole above the Betonamit

human eye can follow the crack beyond the penetration depth of the resin.

\section{Results and Discussion}

The procedure described in the previous chapter is the result of an empirical study during which all parameters have been varied carefully, e.g. reinforcement position, blind hole spacing, diameter and depth, and the filling level of the expansive grout. There were many failed attempts which led to unstable or irreproducible cracks. In general, the balance between the expanding force of the Betonamit must be matched by the reinforcement to allow and, at the same time, to limit the crack growth. All variations of parameters have some unavoidable uncertainties, but altogether the procedure has proven to be robust against small changes as they naturally occur in a concrete laboratory.

After many tests to optimize the parameters, reproducible results were obtained with the parameter values given in Table 2. Five specimens were built and the results analyzed. Variations in the procedure affected the curing time, depth and diameter of the blind holes, and the position of the center reinforcement. For each of the specimens the crack depth was measured. Table 3 summarizes the specimens, test parameters, and results.

The expanding mortar creates a slowly increasing expansion pressure of up to 0.9 tons $/ \mathrm{cm}^{2}$ in the blind holes, and thus leads to the opening of cracks. In all experiments cracks were created, which were visible at the surface of the specimens running within a corridor of $1-2 \mathrm{~cm}$ left and right of the direct line through the row of blind holes (alignment parameter in Table 1).
Between the edges of the specimen and the first and last blind holes the crack pattern shows larger deviations, and in most cases, a V-shaped crack pattern develops. These areas are not included in the crack analysis.

The width of the cracks at the surface is mostly below $0.2 \mathrm{~mm}$ and varies along the length of the cracks. This crack width is within the lower limit range of what is regarded as being significant for concrete structures. Wider cracks could be created by using larger volumes of Betonamit in blind holes which can hold larger volumes. However, the cracks created in this study should serve as a reference for NDT methods and leave enough unbroken space below for this reason.

In most cases, the top of the blind holes shows funnelshaped breakouts at the surface, which appear at the end of the expansion process. These damages do not affect the width or depth of the cracks. However, they may be obstructing measurements, e.g. for ultrasonic probes, where a smooth surface is required for the transducers. In such cases, the breakouts can be repaired with mortar.

An experienced civil engineer might be able to recognize the exact position of a crack tip in a photograph, while rather inexperienced personnel might find different results. Typically, the human factor plays a major role in visual inspection, but is not determined separately in this study.

The crack "Depth" has been evaluated by seven inspectors with different background and experience (ranging from nil to very experienced) on digital high resolution photographs on the computer screen to avoid any influence by the inspection through the lighting condition which may vary at the respective point in time when the inspection takes place. The statistical analysis of the result of this analysis revealed a standard deviation of less than $5 \%$.

The opening "Width" of the cracks was in the order of maximum allowed crack width for typical PT concrete structures [5]. There was little variation in the crack width, justifying a reduction in the number of readings for some specimens (\#6-\#8).

The "Shape" of the cracks was determined in the high resolution photographs as the maximum deviation from the straight line given by the prolongation of the blind hole at the origin of the crack. This is visualized in Fig. 3 as the width of the grey bars which represent the results of the cracks created in the respective specimen.

The parameter "Alignment" quantifies how far the crack line at the surface deviates from the straight (ideal) line through the blind holes which were filled with Betonamit to generate the crack. This value was recorded for specimens \#6-\#8; the magnitude is of the order of the blind hole diameter.

The number of parameters which influence the crack depth is very high. A practical solution to limit the crack growth is to include additional reinforcement along the longitudinal axis 
Table 2 Parameters for crack specimen, best values for even crack depth (\#nn denotes specimen number)

\begin{tabular}{ll}
\hline Parameter & Value \\
\hline Blind hole diameter & $8 \mathrm{~mm}$ (10 mm in \#10 and \#12) \\
Blind hole depth & $60 \mathrm{~mm}$ \\
Grout fill level & $50 \mathrm{~mm}$ (leave $10 \mathrm{~mm}$ at the top empty to avoid \\
& breakout) \\
Blind hole spacing & $80 \mathrm{~mm}$ \\
Reinforcement diameter & $8 \mathrm{~mm}$ (long axis), $12 \mathrm{~mm}$ (other) \\
Additional reinforcement layer cover & $165 \mathrm{~mm}$ \\
\hline
\end{tabular}

Table 3 Results of depth, width, shape and alignment of cracks in specimens \#6-\#12

Fig. 3 Visualization of crack depth and shape for specimens \#6, \#7, \#8, \#10, \#12. The pointed line depicts the average value for the crack depth and the crack shape, the dark grey areas represent the respective standard deviations. The solid curved line symbolizes a crack. The depth position of the center reinforcement is indicated by a dashed line. Numerical values for shape (S) and depth (D) are given above (see Tables 1 and 3 for explanations and values)

\begin{tabular}{llllll}
\hline Specimen & $\begin{array}{l}\text { Concrete cover } \\
\text { of center } \\
\text { reinforcement } \\
(\mathrm{mm})\end{array}$ & $\begin{array}{l}\text { Crack depth } \\
\text { mean value } \\
(\mathrm{mm}) / \mathrm{SD}(\mathrm{mm})\end{array}$ & $\begin{array}{l}\text { Shape mean } \\
\text { value }(\mathrm{mm}) / \mathrm{SD} \\
(\mathrm{mm})\end{array}$ & $\begin{array}{l}\text { Width } \\
(\mathrm{mm}) / \mathrm{SD}(\mathrm{mm})\end{array}$ & $\begin{array}{l}\text { Alignment } \\
(\mathrm{mm}) / \mathrm{SD}(\mathrm{mm})\end{array}$ \\
\hline$\# 6$ & 125 & $138 / 16.3$ & $20.9 / 8.9$ & $0.13 / 0.05$ & $7.0 / 3.0$ \\
$\# 7$ & 85 & $94.3 / 22.8$ & $22.9 / 13.0$ & $0.10 / 0.06$ & $8.2 / 5.3$ \\
$\# 8$ & 165 & $131 / 17.1$ & $37.9 / 13.3$ & $0.21 / 0.02$ & $7.3 / 3.8$ \\
$\# 10$ & 125 & $90.8 / 30.4^{\mathrm{a}}$ & $7.7 / 5.5^{\mathrm{a}}$ & $\mathrm{n} / \mathrm{a}$ & $\mathrm{n} / \mathrm{a}$ \\
$\# 12$ & 165 & $136 / 22.6^{\mathrm{b}}$ & $20.8 / 10.6^{\mathrm{b}}$ & $\mathrm{n} / \mathrm{a}$ & $\mathrm{n} / \mathrm{a}$ \\
\hline
\end{tabular}

$n / a$ not available for this specimen

${ }^{a}$ Blind hole $8 \mathrm{~mm}$ diameter, $60 \mathrm{~mm}$ depth, $50 \mathrm{~mm}$ filling

${ }^{\mathrm{b}}$ Blind hole $10 \mathrm{~mm}$ diameter, $60 \mathrm{~mm}$ depth, $50 \mathrm{~mm}$ filling

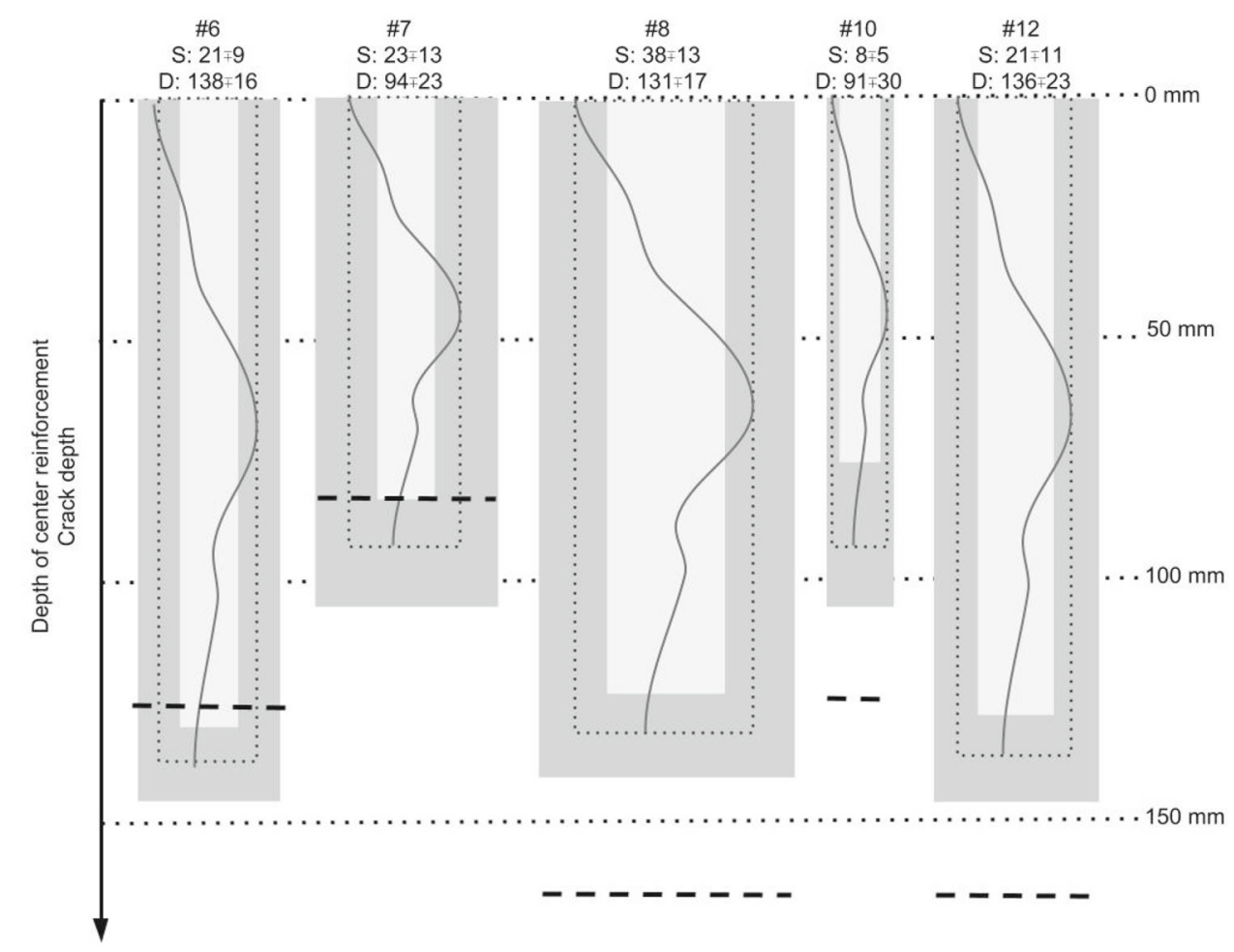

of the specimen perpendicular to the cracks. Three different positions of this layer have been realized in the experiments: the center reinforcement was placed at $8.5 \mathrm{~cm}, 12.5 \mathrm{~cm}$ and $16.5 \mathrm{~cm}$ concrete cover.
The results for specimens \#6, \#7, \#8, \#10 and \#12 are summarized in Table 3. For \#6, \#7, \#8 the blind hole diameter was $8 \mathrm{~mm}$ with a depth of $50 \mathrm{~mm}$. The filling height of the expanding mortar in the blind hole was in the range of $35-40 \mathrm{~mm}$. For \#10 and \#12 a larger filling height of $50 \mathrm{~mm}$ 
in a $60 \mathrm{~mm}$ blind hole ( $8 \mathrm{~mm}$ diameter in \#10/10 $\mathrm{mm}$ in \#12) was chosen.

The result confirms that natural cracks can be produced following the procedure developed in this study. The uncertainty of the found crack depth is in the order of the maximum aggregate size of the concrete used for the specimen. It cannot be expected to define a structural crack property smaller than the inhomogeneity of the material, characterized by the maximum aggregate size. The quantitative description of the cracks through the four properties allows an independent comparison and quantification of the cracks.

\section{Conclusions}

This procedure has been repeated in the laboratory and is used now regularly for creating cracks with predefined properties for the development and validation of methods for NDE of cracks, especially crack depth.

A round robin test with international participants is being organized to study the influence of local material and conditions to the result. Ultimately, a procedure should be established which enables any laboratory to create well defined cracks and compare the results of NDE on them quantitatively with results achieved elsewhere. Once established, the availability of a reference specimen with known crack properties will lead to an improved performance comparison of NDT equipment and procedures.

Cracks occurring in existing concrete structures generally are different from the ones described in this study. Due to the variability and uniqueness of the natural cracks, their use for the purpose described above seems impossible.

Modeling of controlled crack [22, 23] creation may be useful to initiate cracks within a wider range of properties. It would be advantageous to have cracks of a larger opening width and to evolve the procedure to cover this property accordingly. Up to now, the ground truth for depth and shape of the cracks can only be established by cutting the specimen. An independent method without the need of special equipment would be helpful. A reliable automated image processing tool to identify the cracks in the photographs could be useful to make the crack depth analysis independent of human inspectors and would safe time. Such studies will be included in future research.

The method reported in this study to create surface breaking cracks can, in principle, also be used to initiate delaminations which are of high interest in the deterioration process of bridge decks.

Open Access This article is distributed under the terms of the Creative Commons Attribution 4.0 International License (http://creativecomm ons.org/licenses/by/4.0/), which permits unrestricted use, distribution, and reproduction in any medium, provided you give appropriate credit to the original author(s) and the source, provide a link to the Creative Commons license, and indicate if changes were made.

\section{References}

1. Crow, J.M.: The Concrete Conundrum. Chemistry World, pp. 62-66 (2008)

2. Aligizaki, K.K.: Pore Structure of Cement-Based Materials: Testing, Interpretation and Requirements. CRC Press, Boca Raton (2005)

3. Wiggenhauser, H., Azari, H.: Classification of nondestructive evaluation tasks for reinforced concrete structures. J. Infrastruct. Syst. 23, 04017021 (2017)

4. French, W.J.: Presidential Address 2003: Why concrete crack$\mathrm{s}-$ geological factors in concrete failure. Proc. Geol. Assoc. 116, 89-105 (2005)

5. DIN EN 1992-1-1: Eurocode 2: design of concrete structures-Part 1-1: General rules and rules for buildings; German version (2010)

6. Arne, K.C.: Crack Depth Measurement in Reinforced Concrete Using Ultrasonic Techniques. Master Thesis, Georgia Tech Theses and Dissertations [20366] School of Civil and Environmental Engineering Theses and Dissertations [1499] (2014)

7. Hollis, N., Walker, D., Lane, S., Stutzman, P.E.: Petrographic Methods of Examining Hardened Concrete: A Petrographic Manual. FHWA (2006)

8. Brigante, M., Sumbatyan, M.A.: Acoustic methods for the nondestructive testing of concrete: A review of foreign publications in the experimental field. Russ. J. Nondestr. Test. 49, 100-111 (2013)

9. Helmerich, R., Mielentz, F., Milmann, B., et al: Detection of cracks perpendicular to the surface using acoustic methods. In: International Symposium Non-Destructive Testing in Civil Engineering (NDT-CE). Bundesanstalt für Materialforschung und-prüfung (BAM), Berlin, TU Berlin, Germany (2015). www.ndt.net/id=184 12

10. Liu, P.-L., Lee, K.-H., Wu, T.-T., Kuo, M.-K.: Scan of surfaceopening cracks in reinforced concrete using transient elastic waves. NDT E Int. 34, 219-226 (2001)

11. DIN EN 583-6: Non-destructive testing-Ultrasonic examination-Part 6: Time-of-flight diffraction technique as a method for detection and sizing of discontinuities (2008)

12. Sansalone, M., Streett, W.B.: Impact-Echo: Non-destructive Evaluation of Concrete and Masonry. Bullbrier Press, Ithaca, NY (1997)

13. Krüger, M.: Scanning impact-echo-techniques for crack depth determination. Otto-Graf-J. 16, 245-257 (2005)

14. Grosse, C.-U., Reinhardt, H.-W., Krüger, M., Beutel, R.: Application of impact-echo techniques for crack detection and crack parameter estimation in concrete. In: 11th International Conference on Fracture-ICF 11 Politecnico di Torino, pp. 4884-4889 (2005)

15. Zoidis, N., Tatsis, E., Vlachopoulos, C., et al.: Inspection, evaluation and repair monitoring of cracked concrete floor using NDT methods. Constr. Build. Mater. 48, 1302-1308 (2013)

16. Krause, M., Mielentz, F., Milmann, B., et al.: Imaging of cracks and honeycombing in concrete elements. In: Acoustical Imaging, pp. 129-137 (2004)

17. Friese, M., Effner, U., Mielentz, F., Helmerich, R.: Capabilities of non-destructive testing of RC structures-quality assurance for crack repair using ultrasonic echo. In: Bridge Maintenance, Safety and Management, pp. 309-309 (2010)

18. Müller, S., Niederleithinger, E., Bohlen, T.: Reverse time migration: a seismic imaging technique applied to synthetic ultrasonic data. Int. J. Geophys. 2012, 1-7 (2012) 
19. Otsuka, K., Takeda, M.: Detection of fine cracks by x-ray technique with contrast medium in concrete. Doboku Gakkai Ronbunshu 2003, 143-156 (2003)

20. Davis, C.W.: The swelling of bentonite and its control. Ind. Eng. Chem. Res. 19, 1350-1355 (1927)

21. KUBATEC BMT AG/Ltd/SA Widaustrasse 3 FL-9491 Ruggell Liechtenstein. Betonamit (2018). https://www.betonamit.com/
22. Benboudjema, F., De Sa, C., Lagier, F.: Prediction of cracks in concrete due to strain incompatibilities at the mesoscopic scale. In: Computational Modelling of Concrete Structures, pp. 415-422 (2014)

23. Hofstetter, G., Meschke, G.: Numerical Modeling of Concrete Cracking. Springer, Vienna (2011) 